\title{
A Rare Case of a Combination of Tessier Cleft 0 and 3 in a 4-Year-Old Child-A Case Report
}

\author{
Bibhuti Bhusan Nayak $\quad$ M. Lopamudra ${ }^{1}$ \\ ${ }^{1}$ Department of Plastic Surgery, SCB Medical College, Cuttack, \\ Odisha, India
}

Indian J Plast Surg 2019;52:250-251

\begin{abstract}
Address for correspondence M. Lopamudra, MBBS, MS(General Surgery), MCh(Plastic Surgery), Department of Plastic Surgery, SCB Medical College, Cuttack 753001, Odisha, India (e-mail: drlopam@gmail.com).
\end{abstract}

\begin{abstract}
Keywords

- Tessier cleft 0

- Tessier cleft 3

- facial cleft

Description and successful management of a patient with Tessier no. 0 and 3 facial cleft is being presented. Appropriate evaluation was done to rule out the presence of median cleft face syndrome. Lip cleft was repaired by straight line technique with staggering at the vermilion border. Nasal cleft was reconstructed by a transposition flap and the flap taken from the upper lip after correction of the midline cleft. Satisfactory outcome was achieved for this singular deformity by conforming to the basic tenets of plastic surgery.
\end{abstract}

Sir,

Congenital craniofacial clefts are malformations of the cranium and face with deficiencies or excesses of tissue along an anatomic line based on embryologic maldevelopment. The anatomical classification was proposed by Paul Tessier. ${ }^{1}$ Oblique facial clefts are extremely rare congenital deformities with a reported incidence of $0.24 \%$ of all facial clefts. ${ }^{2}$ We present a case of combination of Tessier cleft 0 and 3 in a child.

A 4-year-old child presented to us with midline cleft of the lip and cleft of the left nasal ala (-Fig. 1). There was a groove in the left nasal ala with a deficiency of the lower lateral cartilage. The nasolabial area, lower eyelid, and infraorbital regions were normal. The columella was normal dimensionally but was slightly deviated to the right side. There was an incomplete cleft in the midline extending to the Cupid's bow with widened philtrum. The distance between the philtral columns was $12 \mathrm{~mm}$ at the columellar end and $20 \mathrm{~mm}$ in between the peaks of the Cupid's bow. Intraorally there were two frenula and a gap in between the upper central incisors. Slight depression was palpable in the intact alveolus in the midline. Rest of the oral structures was normal. Computed tomography (CT) of the craniomaxillofacial skeleton was performed to rule out median cleft face syndrome, encephalocele, and holoprosencephaly. Patient had hypertelorism. Based upon the clinical examination and CT scan findings, a diagnosis of Tessier No. 0 and 3 facial cleft was made. The incomplete median cleft lip was repaired first by marking the peak of the Cupid's bow on either sides. After keeping $2 \mathrm{~mm}$ medial to the peak of the
Cupid's bow on both sides, the excess tissue was marked. A full-thickness flap was raised from midline lip tissue islanded on the left superior labial artery (-Fig. 2). The tissue transferred to nose did not contain any vermillion tissue. This flap was planned inferiorly so that skin element of the lip could be transferred to the nasal defect and islanding possible on superior labial artery. The lip was repaired by apposing the mucosa, orbicularis muscle, and skin in the midline. The nasal

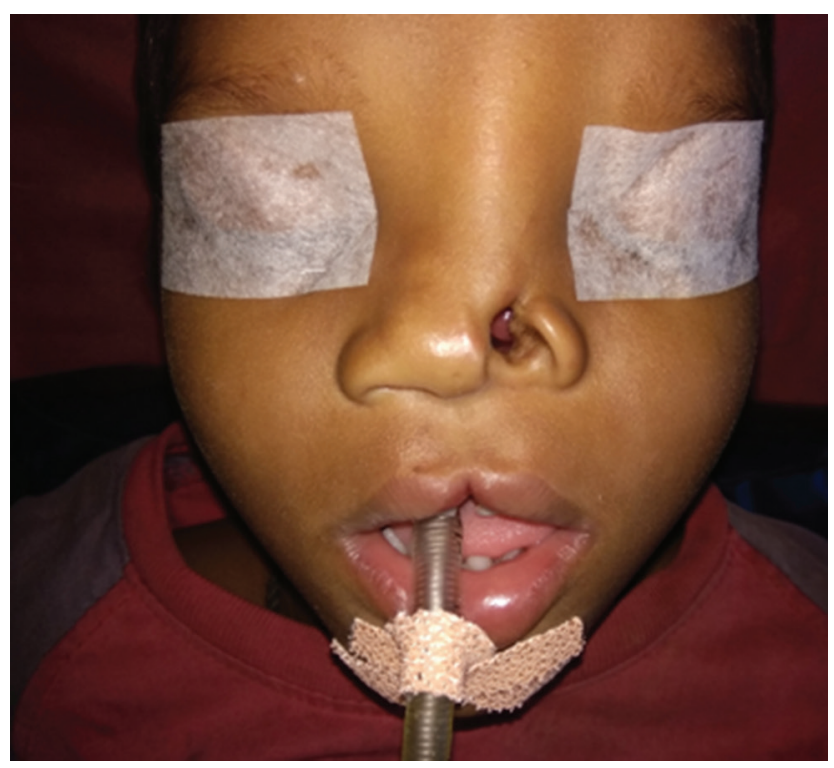

Fig. 1 Midline cleft of the upper lip and cleft of the left nasal ala in a 4-year-old child (preoperative picture).
License terms

(1) (1) $\odot \circledast$ 


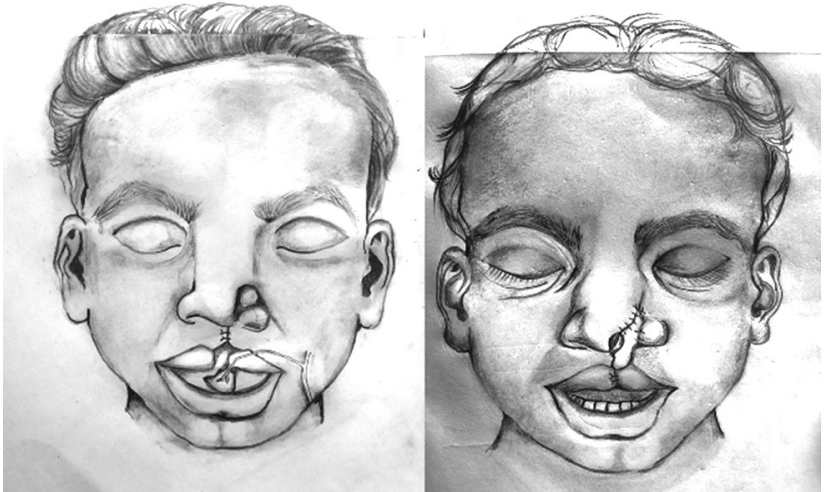

Fig. 2 Schematic diagram. A full-thickness flap was raised from midline lip tissue islanded on left superior labial artery (left). The nasal defect covered was covered with the flap raised from the midline of upper lip (right).
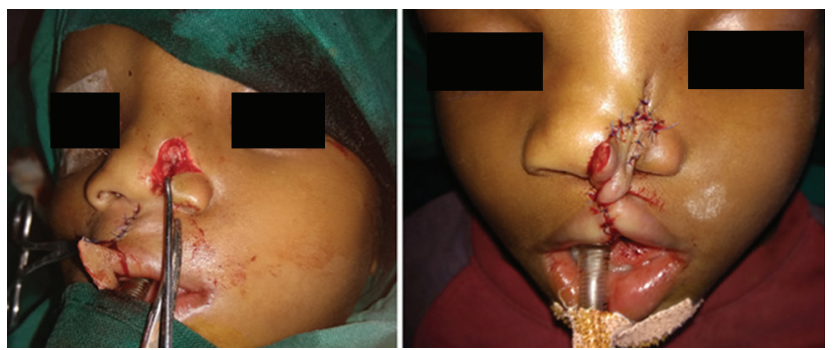

Fig. 3 Incomplete median cleft lip was repaired. A full-thickness flap was raised with the base at the upper lip and vascular supply from the superior labial artery. The nasal cleft was repaired by a full-thickness transposition flap of the nasal ala which was turned down to match the level of the other side (left). The residual defect was covered with the flap raised from the upper lip (right).

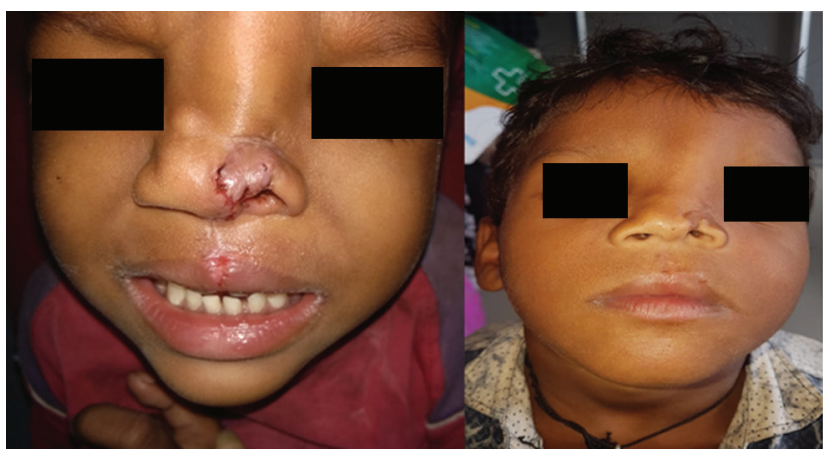

Fig. 4 The flap was healthy and flap detachment was done on postoperative day 10 (left). The 6-month follow-up picture (right). cleft was repaired by a full-thickness transposition flap of the nasal ala which was turned down to match the level of other side. The residual defect was covered with the flap raised from the upper lip ( - Fig. 3). The flap was healthy and flap detachment was done on postoperative day 10 . The aesthetic outcome was well acceptable. A 6-month follow-up picture is shown in - Fig. 4.

A combination of Tessier cleft 0 and 3 is rare. The procedures mentioned are the nasolabial flap, ${ }^{3,4}$ forehead flap, and alar transposition flap. ${ }^{5,6}$ These lead to visible scars. The idea of using the tissue from midline of the lip, which would have been discarded anyway, has been uniquely used with no additional scars. The limitation is the amount of tissue availability from the lip area. The management is unique and innovative since no such reports are available in the literature.

\section{Declaration of Patient Consent}

The authors certify that they have obtained all appropriate patient consent forms. In the form the patient(s) has/have given his/her/their consent for his/her/their images and other clinical information to be reported in the journal. The patients understand that their names and initials will not be published and due efforts will be made to conceal their identity, but anonymity cannot be guaranteed.

\section{Financial Support and Sponsorship}

Nil.

\section{Conflicts of Interest}

There are no conflicts of interest.

\section{References}

1 Tessier P. Anatomical classification facial, cranio-facial and latero-facial clefts. J Maxillofac Surg 1976;4(2):69-92

2 Gawrych E, Janiszewska-Olszowska J, Chojnacka H. Tessier type 3 oblique facial cleft with a contralateral complete cleft lip and palate. Int J Oral Maxillofac Surg 2010;39(11):1133-1136

3 Reddy SG, Reddy RR, Obwegeser J, Mommaerts MY. Options for the nasal repair of non-syndromic unilateral Tessier no. 2 and 3 facial clefts. Indian J Plast Surg 2014;47(3):340-345

4 Giglio A, Ruschel FF, Barcellos C, Pavelecini M, Chem RC. Rotation and advancement flap of the cheek in the treatment of rare craniofacial clefts. J Craniofac Surg 2008;19(5):1411-1415

5 Cizmeci O, Kuvat SV. Tessier no. 3 incomplete cleft reconstruction with alar transposition and irregular z-plasty. Plast Surg Int 2011;2011:596569

6 Mishra RK, Purwar R. Formatting the surgical management of Tessier cleft types 3 and 4. Indian J Plast Surg 2009;42(1, Suppl):S174-S183 